Guidelines Article

\title{
Guidelines for Migrant Workers Reaching their Homes for Prevention and Control of Covid- I 9
}

\author{
Pratima Gedam', Jugal Kishore ${ }^{2}$
}

${ }^{1}$ Assistant Professor, ${ }^{2}$ Director Professor \& Head, Department of Community Medicine, VMMC \& Safdarjung Hospital, New Delhi. DOI: https://doi.org/10.24321/2455.7048.202016

\section{I $\quad \mathbf{N} \quad \mathbf{F} \quad \mathbf{O}$}

\section{Corresponding Author:}

Jugal Kishore, Community Medicine, Vardhman Mahavir Medical College \& Safdarjung Hospital, New Delhi, India.

E-mail Id:

drjugalkishore@gmail.com

Orcid Id:

https://orcid.org/0000-0001-6246-5880

How to cite this article:

Gedam P, Kishore J. Guidelines for Migrant Workers Reaching their Homes for Prevention and Control of Covid-19. Epidem Int 2020; 5(2): 45-46.
India is fighting against the pandemic of Corona virus infection. Just like rest of the world now cases have started raising in India. Till date maximum patients of COVID-19, are concentrated in the metropolitan cities and big towns. Our villages and small towns are still protected from the cases and infection of corona virus. Ongoing lockdown has created a fear and confusion in the minds of people who are economically backward regarding the availability of daily wages and food in the cities. Also, there is a fear in the minds of people of getting infected by corona virus if they stay more in the big cities like Delhi, Mumbai, Hyderabad etc. Because of which many of the labourers and workers have started travelling back to their home towns or towards their villages.

If you are among those who have travelled back to their home town or village via a crowded bus or vehicle be aware! You might be carrying corona virus infection inside your nose and throat.

Are you aware that a person infected with corona virus infection does not show any sign or symptom for first 2 to 14 days after getting infected by corona virus (as Incubation period of corona virus is 2 to 14 days)? Because of which you are not aware whether you are carrying a corona virus in your nose and throat or not. In this situation if you have recently travelled through heavily crowded buses, trains or vehicles please be aware and follow below given preventive measures to keep yourself and your family healthy.

As soon as you reach your home town or village in rural area health workers may screen you for signs of upper respiratory tract infection. If they find that you are suffering from upper respiratory tract infection, then they will ask you to quarantine in a place identified by health department of the state for quarantine purpose. There they will take a nasopharyngeal swab and will send it to labs for RT-PCR, for detecting corona virus infection. Test results will come in two to three days till then you have to co-operate health workers and remain quarantine in the same building. If your test results come negative, they will allow you to go to your home. But if your test results come positive health workers and doctors will keep you in isolation till your two tests report done 24 hours apart will come negative. If during screening you are not symptomatic or does not give any history of contact with suspected or confirmed case, then they will allow you to go home immediately. 
Remember corona infection can be dangerous for your family member particularly older parents, relatives and pregnant ladies. After reaching home there are certain simple preventive measures you should follow to keep yourself and your family safe and healthy:

- As soon as you reach home don't hug and meet family members too closely. Maintain a distance of at least 1 meter between you and your family members.

- Before entering house wash your hands and legs properly with soap and water, while doing this see that you should rub soap on your hands at least for 20-30 seconds.

- Whatever luggage and bags you are carrying with you keep them outside your home under sun at least for one day, so that we can disinfect all your luggage by using sun rays.

- As soon as you enter the house head towards the bathroom and have a clean bath with hot water and soap.

- Wash your own clothes with regular detergent and hot water and dry them under sunlight.

- After this as much as possible restrict your movement inside one room and avoid attending social gatherings in the community or don't allow visitors to visit you, at least for 14 days.

- Wash your hands every 2-3 hourly with soap and water.

- Cover your face with handkerchief or tissue paper while coughing and sneezing. If both are not available you can use your upper sleeve, not your hands. Burn your used tissue papers to disinfect them.

- Do not touch your face, eyes and nose again and again, unnecessarily.

- If you have any doubt in the mind regarding, you have traveled along with any suspected case of corona virus or who has any signs of upper respiratory tract infection in recent past then you should be more careful and vigilant. In such situation it will be better to get home quarantined. In that case you have to stay in a separate room, alone for next 14 days.

- $\quad$ Please prefer a room for home quarantine with attached toilet bathroom. It should be well ventilated and with large windows.

- Whatever electronic gadgets like mobile and remote you are using in that room should not be touched by other family members.

- Limit the number of caregivers. Ideally, assign one person who is in good health and has no underlying chronic or immuno-compromising conditions.

- Visitors should not be allowed until you completely recover and has no signs or symptoms of COVID-19.

- Clean and disinfect bathroom and toilet surfaces at least once daily with regular household soap or detergent and then with disinfectant containing $0.1 \%$ sodium hypochlorite.

- Do not share utensils and clothes and beddings used by you with other family members. Wash and clean clothes and utensils used by you on your own to avoid infection to other family members.

- Have healthy, vegetarian balanced diet with plenty of water.

- Enough rest (sleep of 7-9 hours per day), practice of yoga and meditation will improve your immunity to fight against the corona virus infection.

- You can do salt water gargles and drink lukewarm water during this period to keep your respiratory tract free from microorganisms.

- COVID-19 is not a sexually transmitted disease but can transmit because of close contact and touch. Avoid sexual contact with your spouse during this period.

- During these 14 days of quarantine do not drink alcohol or smoke as, alcohol reduce immunity and smoking make respiratory tract more prone for infection.

- Stay away from vulnerable members of the family and society like old age people (>60 years), pregnant woman, children $\&<10$ years of age, persons suffering from hypertension, diabetes mellitus, kidney failure, liver failure, AIDS, lung disease, heart disease etc.

- During this period of home quarantine if you develop any symptom like dry cough, fever or difficulty in breathing, immediately contact health workers or call on $24 * 7$, toll free helpline number: 1075 . They will guide you and suggest you further treatment.

Last but not the least, case fatality rate from corona virus infection is $2-4 \%$, rest all 96 to $98 \%$ patients get totally cured with proper treatment and care.

So, don't be afraid of corona. Stay Home, Stay Safe and Stay Healthy! 